\title{
Experiência de docentes do Ensino Médio em Conduzir Atividades Remotas Durante o Distanciamento Social: uma Análise Baseada no Contexto da Educação 4.0
}

\author{
Ana Paula Juliana Perin \\ Universidade Federal do Paraná \\ Curitiba, PR, Brasil \\ apjperin@inf.ufpr.br
}

\author{
Deivid Eive Silva \\ Universidade Federal do Paraná \\ Curitiba, PR, Brasil \\ desilva@inf.ufpr.br
}

\author{
Natasha Malveira C. Valentim \\ Universidade Federal do Paraná \\ Curitiba, PR, Brasil \\ natasha@inf.ufpr.br
}

\begin{abstract}
In Education 4.0, it is expected a personalized learning process and that students are the protagonist. In this new education format, it is necessary to prepare students with the skills and competencies of the 21st Century, such as teamwork, creativity, and autonomy. In this context, this paper aims to present the outcomes of a survey about the high school teachers' experiences with online activities during social distance provoked by the COVID-19 pandemic. Thus, this survey can help understand the experiences and degree of difficulty of high school teachers when using technological resources in online classes in the period of social distance. Moreover, we investigated the skills and competencies of the 21st Century perceived by teachers in students. The outcomes showed that many teachers felt difficulties to use technological resources. Besides, some of the teachers noticed in students skills of the 21st Century, including concentration, autonomy, and motivation.
\end{abstract}

\section{KEYWORDS}

Educação 4.0, Experiência de docentes, Ensino Remoto, Século XXI.

\section{INTRODUÇÃO}

Atualmente, percebe-se a necessidade de uma educação mais alinhada ao mundo contemporâneo que prepare os estudantes para os desafios do Século XXI como lidar com os recursos e os processos tecnológicos emergentes. Essa necessidade motivou um novo formato de aprendizagem conhecido como Educação 4.0 [1].

Nessa perspectiva, o desenvolvimento de competências e habilidades relacionadas a aprendizagem autônoma dos estudantes se mostra necessário para preparar os estudantes para o mundo contemporâneo [2]. Assim, ambientes mais colaborativos podem ser propostos com a finalidade de permitir a interação, experimentação e conexão entre os estudantes, além de servir como uma alternativa ao modelo tradicional de sala de aula, sendo possível trabalhar o protagonismo dos estudantes e o desenvolvimento de competências e habilidades do Século XXI. Dentre as competências e habilidades importantes para o desenvolvimento dos estudantes, podem ser citadas: domínio de tecnologia, liderança, colaboração, boa comunicação, inteligência emocional, autonomia, trabalho em equipe, dentre outras [3]. Dessa maneira, acredita-se que será possível preparar futuros profissionais mais aptos para tomar decisões e resolver problemas de forma criativa e colaborativa, além de ter uma mentalidade dinâmica para aprender novos conhecimentos[4]

O docente, por sua vez, pode facilitar o desenvolvimento das competências e habilidades nos estudantes, combinando o conhecimento pedagógico com atividades práticas a fim de aproximar os mais diversos recursos da era digital da sala de aula [5]. De acordo com o Comitê Gestor da Internet (CGI) no Brasil [6], 76\% dos docentes brasileiros estão buscando cada vez mais formação no uso e integração de recursos tecnológicos às suas atividades educacionais. Contudo, foi percebido quanto mais avançada é a idade do docente, menos este docente tem interesse em utilizar os recursos tecnológicos [6]. Conforme, os dados do Centro de Inovação para a Educação Brasileira (CIEB) [7], no último semestre de 2019, 48\% dos docentes das escolas públicas fizeram o uso da Internet apenas para enviar conteúdo aos estudantes. Estes dados mostram que mesmo o docente recebendo capacitação para o uso dos recursos tecnológicos, o mesmo tem pouco acesso ou não utiliza todo o potencial que estes recursos podem oferecer para a área da educação. Entretanto, em 2020, muitos docentes receberam o desafio de construir e promover novas formas de ensinar e aprender, sendo necessário o uso de inovações tecnológicas e interativas, a fim de conduzir atividades de maneira remota, devido ao fechamento das instituições educacionais e a interrupção de aulas e atividades presenciais ocasionado pela pandemia da COVID-19 [8].

Durante o período de pandemia, passou-se a discutir com mais frequência as dificuldades do docente em relação ao uso dos recursos tecnológicos como apoio aos processos de ensino e aprendizagem. Neste sentido, este artigo tem o objetivo de apresentar os resultados de uma pesquisa de opinião sobre o processo de adaptação, aceitação e adoção dos recursos tecnológicos em atividades remotas durante o período pandêmico por docentes do Ensino Médio. Nesta perspectiva, este estudo foi direcionado a este nível de ensino, pois segundo dados do Programa Internacional de Avaliação de Estudantes (PISA) [9] e Sistema de Avaliação da Educação Básica (SAEB) [10], o Ensino Médio apresenta baixos rendimentos escolares. Segundo dados do SAEB de 2017, este nível de ensino encontra-se estagnado desde 2009. Dados do PISA de 2018 [11], apresentam uma pequena evolução no desempenho dos estudantes do Ensino Médio, mas que ainda precisa ser melhorado.

Esta pesquisa de opinião foi realizada por meio de um questionário produzido no Google Forms, seguindo três passos: (1) planejamento (elaboração e validação do questionário), (2) execução (compartilhamento e monitoramento do questionário), e (3) análise das respostas dos docentes. O questionário foi organizado em três partes, sendo elas: (a) caracterização dos docentes: com o objetivo de entender qual o perfil dos respondentes; (b) experiência dos docentes nas atividades remotas: com o objetivo de identificar as vivências dos respondentes na condução de aulas no período pandêmico; e (c) percepção dos docentes sobre os estudantes nas atividades remotas: com o objetivo de compreender a visão dos 
docentes em relação a participação e o desenvolvimento dos estudantes durante as atividades remotas.

Este artigo está organizado em 6 Seções. Na Seção 2, são apresentados o Background sobre a evolução da educação, indo de uma Educação 1.0 até chegar a uma Educação 4.0, e trabalhos relacionados sobre a educação durante o período pandêmico. Na Seção 3 é descrita a metodologia adotada para a realização da pesquisa de opinião. Na Seção 4 são mostrados os dados de caracterização dos participantes. Na Seção 5 são mostrados os resultados e discussões da pesquisa de opinião. Por fim, na Seção 6 são apresentadas as conclusões e os próximos passos da pesquisa.

\section{BACKGROUND}

A educação pode ser caracterizada em 04 fases, sendo 1.0, 2.0, 3.0 e 4.0. Nesse sentido, foi percebida que a educação foi se adaptando ao longo do tempo com a finalidade de apoiar os modos de produção gerados pelas revoluções industriais [12].

A Educação 1.0 (Primeira Revolução Industrial) é conhecida pela relação docente-estudante, onde não havia a padronização do currículo e o objetivo do ensino estava direcionado na capacidade de leitura, escrita e cálculos [13]. Na Educação 1.0, o docente detinha toda a informação e os estudantes somente recebiam a informação e não tinham papel ativo no processo de aprendizagem [12], se caracterizando como uma educação mais tradicional.

A Educação 2.0 (Segunda Revolução Industrial) exigiu dos estudantes habilidades de leitura e escrita, provocando a necessidade de aperfeiçoamento/treinamento de pessoas para atuarem na linha de produção [13]. Na Educação 2.0, o estudante já não era visto como um sujeito totalmente passivo no processo de aprendizagem e o ensino era baseado na memorização das informações para operar as máquinas e ferramentas de trabalho [14]. Desse modo, o docente era visto como facilitador da aprendizagem, o que permitiu aumentar o nível de interação entre docente e estudante [15].

A Educação 3.0 (Terceira Revolução Industrial) é caracterizada pela chegada dos computadores. Na Educação 3.0, a troca de informações foi constante entre estudantes e docentes, promovendo suporte para o auto-aprendizado e, assim, o estudante foi preparado para criar conhecimento e para não apenas consumi-lo [14] [13]. É certo que a tecnologia permite aos estudantes acesso ilimitado às fontes de informações, promovendo suporte para o aprendizado autônomo. Porém, o processo de ensino e aprendizagem não mudaram pois a forma de ensino ainda está alinhado ao modelo de ensino da Educação 2.0 [13].

A Educação 4.0 (Quarta Revolução Industrial) requer uma educação mais alinhada ao mundo contemporâneo, onde os estudantes sejam preparados para os desafios do Século XXI e sejam protagonistas do seu aprendizado [13]. Assim, a Educação 4.0 está alinhada a uma nova forma de ensino, onde o objetivo é preparar os estudantes para desenvolver conhecimentos, habilidades e experiências em todos os aspectos da vida [14]. Desse modo, a sala de aula pode ser configurada no contexto da Educação 4.0, a partir de algumas características, tais como: a) Personalização do material didático, a fim de atender aos diferentes tipos de aprendizagem; b) Gamificação com elementos lúdicos que auxiliem na motivação e engajamento do estudante; c) atividades adaptadas conforme o conhecimento e a aprendizagem do estudante; e d) métodos de análise para identificar estudantes com dificuldades, entre outros [13]. Contudo, é importante um planejamento e preparação dos docentes para o uso de novas metodologias pedagógicas, valorizando as práticas que contribuem para o estudante ser protagonista do seu próprio aprendizado [16].

\subsection{Educação durante o Período Pandêmico}

Esta seção apresenta alguns estudos sobre o ensino remoto em diferentes contextos, onde é possível compreender o cenário da educação diante do olhar de outros pesquisadores. Desse modo, são apresentados quatro trabalhos, no qual foi identificada a necessidade da formação do docente para o uso dos recursos tecnológicos disponíveis na escola.

Em [17] foi realizado uma revisão da literatura sobre as principais dificuldades dos docentes no uso de novos métodos de ensino e aprendizagem, que podem tornar as aulas mais dinâmicas e potencializar o desenvolvimento dos estudantes. Porém, a falta de tempo pode ser considerada um dos principais motivos que dificultam a capacitação deste docente, pois sua jornada de trabalho é intensa e complexa. Além disso, conhecer e aplicar as diversas metodologias ativas também pode se configurar como uma das dificuldades encontradas pelo docente. Estas metodologias são: Aprendizagem Colaborativa, Aprendizagem Baseada em Problemas, Aprendizagem Baseada em Projetos, dentre outras [18]. No cenário atual, alguns docentes percebem que estas metodologias podem contribuir no processo de aprendizagem, aumentando o engajamento dos estudantes [19]. Além disso, os docentes demonstram interesse no uso de metodologias ativas aliadas às tecnologias disruptivas, tais como: Inteligência Artificial, Internet das Coisas, Plataformas Digitais, dentre outras [17].

Em sequência, foi identificado um estudo sobre a contribuição dos recursos tecnológicos para o ensino remoto no Ensino Superior em período de isolamento social, devido à COVID-19 [20]. Este explica que o uso de recursos como Google Classroom e ZOOM podem possibilitar a interação docente/estudante de forma assíncrona (não sendo necessário a participação do docente e do estudante no mesmo ambiente e ao mesmo tempo) e síncrona (sendo necessário a participação do docente e do estudante no mesmo ambiente e ao mesmo tempo). No entanto, é afirmado que o uso destes recursos não tem a intenção de substituir as atividades presenciais, mas de apoiar os processos de ensino e aprendizagem, tornando as atividades remotas mais motivante, colaborativa, interativa e, principalmente, significativa para os estudantes [20].

Adiante, o estudo [21] fala sobre algumas limitações da Educação a Distância $(\mathrm{EaD})$. Mesmo a $\mathrm{EaD}$ possibilitando o estudo e a pesquisa contínua em período de distanciamento social, esta modalidade de ensino ainda é considerada limitada diante da necessidade de execução de atividades práticas. Sendo assim, a capacitação docente busca preparar o docente para o uso dos recursos tecnológicos a fim de conduzir aulas práticas, personalizadas e interativas. Acreditase que estas práticas podem permitir o estudante transformar a informação em conhecimento e ter experiências positivas na aprendizagem [21].

Além disso, foi identificado uma pesquisa de opinião sobre a experiência do docente nas atividades remotas. Neste estudo, os 
docentes relataram pontos negativos, tais como: (1) aumento na necessidade de atendimento individual aos estudantes e familiares; (2) falta de capacitação dos docentes; (3) falta de infraestrutura tecnológica para os docentes e estudantes; e (4) ausência do contato direto com os estudantes. Os docentes destacaram, como ponto positivo a oportunidade de aprender e testar novas práticas pedagógicas por meio dos recursos tecnológicos [22].

No entanto, os trabalhos citados acima não investigam as competências e habilidades do Século XXI trabalhados nos estudantes durante o ensino remoto. Além disso, nesse estudo buscou-se focar no Ensino Médio pelos motivos já citados na Introdução. Por fim, esta pesquisa de opinião buscou identificar as dificuldades no uso dos recursos tecnológicos, a partir das experiências dos docentes em conduzir atividades remotas no período de distanciamento social.

\section{METODOLOGIA}

As etapas utilizadas para a organização desta pesquisa de opinião foram: (1) planejamento, (2) execução e (3) análise, seguindo o processo experimental proposto por Lazar [23]. Na etapa de planejamento (1), foi definido o público-alvo, sendo estes docentes do Ensino Médio devido aos problemas enfrentados por este nível de ensino. Posteriormente, foi realizada a elaboração de um questionário online, com perguntas relacionadas a experiência dos docentes na realização de atividades remotas. Além disso, foi escolhido o Google Forms para o desenvolvimento do questionário. Em sequência, foi preparado um estudo piloto para verificar a adequação das perguntas para o público-alvo. Desse modo, foram convidados quatro profissionais da educação (1 coordenadora pedagógica e 3 docentes), para avaliar o instrumento de coleta de dados. O estudo piloto possibilitou uma melhor organização e padronização dos termos utilizados, como utilizar somente o termo "recurso tecnológico" ao invés de "recurso computacional". Neste sentido, o questionário foi ajustado e as perguntas foram adequadas para o público-alvo a fim de estabelecer uma maior compreensão dos docentes.

$\mathrm{Na}$ etapa de execução (2), a pesquisa de opinião foi compartilhada e monitorada por meio de aplicativos de compartilhamento de mensagens e de mídias sociais. O período de coleta de dados ocorreu entre os dias 26 de maio de 2020 e 10 de junho de 2020 , totalizando quatorze dias. Ao total, o questionário teve 286 respondentes. As respostas obtidas foram analisadas individualmente $\mathrm{e}$ revisada por pares. Destas 286 respostas, 31 foram descartadas, pois foram respondidas por docentes que não estão desenvolvendo atividades remotas durante o período de distanciamento social. Portanto, foram consideradas 255 respostas para a análise dos dados. Nas seções 4 e 5 a seguir serão apresentadas as análises e discussão dos dados obtidos, etapa (3) desta metodologia.

\section{CARACTERIZAÇÃO DOS DOCENTES}

Os resultados da pesquisa de opinião foram organizados em três partes: 1) dados de caracterização do docente, 2) experiência do docente nas atividades remotas, e 3 ) percepção do docente sobre os estudantes nas atividades remotas. Nessa seção serão apresentados os dados de caracterização do docente. Desse modo, 9 perguntas foram realizadas: 1) Gênero (Masculino ou Feminino); 2) Idade; 3) Nível de ensino que trabalha (Ensino Médio Regular, Profissionalizante Integrado ao Médio ou Educação de Jovens e Adultos);
4) Região que atua como Docente (Norte, Nordeste, Centro-Oeste, Sudeste e sul); 5) Tipo de instituição de ensino que atua (Estadual, Privada ou Federal); 6) Formação Educacional (Ensino Superior, Especialização (Lato Sensu), Mestrado (Stricto Sensu), Mestrado (Stricto Sensu - Cursando), Doutorado (Stricto Sensu) ou Doutorado (Stricto Sensu - Cursando); 7) Disciplina que Ministra; 8) Tempo que atua como docente do Ensino Médio; e 9) Tempo que faz uso dos recursos tecnológicos para o ensino.

Referente ao gênero dos docentes (1), 53,7\% ( $\mathrm{N}=137)$ são do gênero feminino e 46,3\% ( $\mathrm{N}=118)$ são do gênero masculino. Sobre a idade do docente (2), 42,7\% ( $\mathrm{N}=109)$ dos docentes possuem idade entre 31 à 40 anos, 35,3\% ( $\mathrm{N}=90)$, entre 41 à 50 anos, $12,2 \%(\mathrm{~N}=31)$ entre 20 à 30 anos, seguido de $9,8 \%(\mathrm{~N}=25)$ entre 51 à 60 anos. No que diz respeito ao nível de ensino que estes docentes atuam (3), 68,6\% $(\mathrm{N}=175)$ trabalham no Ensino Médio regular, 29\% $(\mathrm{N}=74)$ atendem a educação profissionalizante integrada ao Ensino Médio, e 2,4\% $(\mathrm{N}=6)$ trabalham com Educação de Jovens e Adultos no nível Ensino Médio. Em relação a região que atua como docente do Ensino Médio (4), 79,6\% (N=203) atuam na região Norte, $14,1 \%(\mathrm{~N}=36)$ na região Sul, 3,9\% $(\mathrm{N}=10)$ na região Sudeste, $1,6 \%(\mathrm{~N}=4)$ na região Nordeste e $0,8 \%(\mathrm{~N}=2)$ na região Centro-Oeste. O destaque da região Norte se dá devido a predominância de contatos que os pesquisadores possuem com os professores do Ensino Médio desta região. Quanto ao tipo de instituição onde docentes trabalham (5), 70,2\% ( $\mathrm{N}=179)$ são da rede estadual, $20,8 \%(\mathrm{~N}=53)$ da rede federal e $9 \%(\mathrm{~N}=23)$ da iniciativa privada; o que mostra que a maioria dos respondentes atuam no ensino público: Estadual e Federal $(\mathrm{N}=232)$. No que diz respeito a formação educacional do docente (6), 27,5\% (N=70) possuem Ensino Superior, $40 \%(\mathrm{~N}=102)$ possuem especialização, 15,7\% $(\mathrm{N}=40)$ possuem Mestrado, 7,8\% $(\mathrm{N}=20)$ possuem Doutorado e $0,4 \%(\mathrm{~N}=1)$ possui Pós-Doutorado. Complementando as informações sobre a formação educacional, $4,7 \%(\mathrm{~N}=12)$ atualmente cursam mestrado e $3,9 \%(\mathrm{~N}=10)$ estão no doutorado.

Em relação as disciplinas básicas do Ensino Médio que os docentes ministram (7), pode-se destacar que $11,8 \%(\mathrm{~N}=40)$ ministram a disciplina de Língua Portuguesa, 7,4\% $(\mathrm{N}=25)$ ministram Matemática, 7,4\% $(\mathrm{N}=25)$ ministram Biologia, 7,1\% $(\mathrm{N}=24)$ História, 6,2\% ( $\mathrm{N}=21)$ Inglês, 5,6\% ( $\mathrm{N}=19)$ Química, 5,3\% ( $\mathrm{N}=18)$ Filosofia, 5\% $(\mathrm{N}=17)$ Sociologia, 4,7\% ( $\mathrm{N}=16)$ Artes, 3,8\% ( $\mathrm{N}=13)$ Educação Física e $3,2 \%(N=11)$ Física. Por fim, nas disciplinas específicas do Ensino Médio profissionalizante, $3,8 \%(\mathrm{~N}=13)$ dos docentes ministram a disciplina de Informática, 1,5\% ( $\mathrm{N}=5$ ) Programação ou Lógica de Programação, 0,9\% (N=3) Redes de Computadores, 0,9\% (N=3) Algoritmos e $0,6 \%(\mathrm{~N}=2)$ Administração. Além disso, outras disciplinas que foram menos citadas na pesquisa de opinião foram omitidas do artigo devido a limitação de espaço. No que diz respeito ao tempo que atua como docente do Ensino Médio (8), 7,8\% ( $\mathrm{N}=20)$ disseram atuar a menos de um ano, 35,3\% ( $=90)$ dos participantes atuam entre 1 a 5 anos, $19,6 \%(\mathrm{~N}=50)$ de 6 a 10 anos, $18,4 \%(\mathrm{~N}=47)$ entre 11 e 15 anos, 8,6\% ( $\mathrm{N}=22)$ entre 16 e 20 anos, 10,2\% ( $=26)$ mais de 20 anos. Por fim, em relação ao tempo que faz uso dos recursos tecnológicos para o ensino (9), 1,6\% (N=4) relataram nunca ter usado, $16,5 \%(\mathrm{~N}=42)$ relataram ser seu primeiro ano por causa do distanciamento social, $47,1 \%(\mathrm{~N}=120)$ utilizam de 1 a 5 anos, $21,6 \%$ $(\mathrm{N}=55)$ de 6 a 10 anos, 13,3\% $(\mathrm{N}=34)$ mais de 10 anos, conforme apresentado na Figura 1. 
Há quanto tempo você faz uso dos recursos tecnológicos, para melhor condução das aulas e maior entendimento dos alunos?

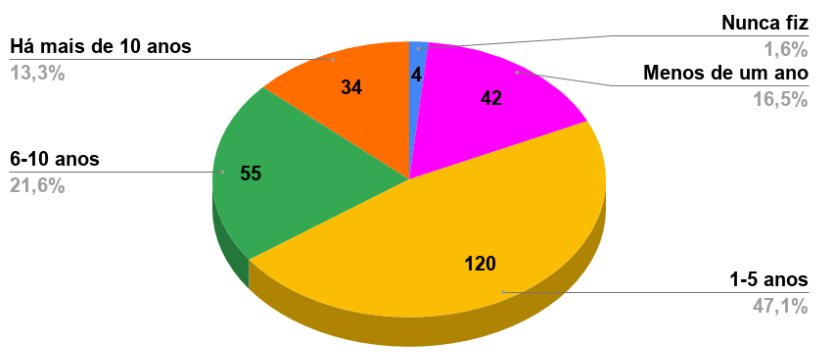

Figure 1: Tempo que faz uso das tecnologias para melhor condução das aulas e atendimento aos estudantes

\section{RESULTADOS E DISCUSSÕES}

Nessa seção são apresentados e discutidos os resultados advindos das questões relacionadas a:

a) experiência do docente nas atividades remotas (7 perguntas):

- 1) "Como docente do Ensino Médio, você utiliza os recursos tecnológicos para quais atividades?";

- 2) "Qual(is) equipamentos(s) tecnológico(s), você utiliza atualmente para realizar atividades de ensino durante o distanciamento social?";

- 3) "Qual(is) recurso(s) tecnológico(s) você utiliza nas suas atividades remotas para ministrar aulas para os estudantes?";

- 4) "Qual(is) recurso(s) tecnológico(s) você utiliza para apoiar suas atividades remotas?";

- 5) Como você considera a sua experiência nas atividades remotas com os estudantes?";

- 6) "Como você avalia a sua adaptação do ensino presencial para o ensino remoto?"; e

- 7) "Qual foi o grau de dificuldade em usar os recursos tecnológicos nas atividades remotas?";

e (b) percepção do docente sobre os estudantes nas atividades remotas (04 perguntas):

- 1) "Os estudantes se mostram criativos utilizando os recursos tecnológicos para resolver as atividades propostas, solucionar desafios-problemas, tomar decisões em grupos, dentre outros?";

- 2) "Nas atividades remotas, você tem percebido nos estudantes o desenvolvimento de competências e habilidades do Século XXI, como raciocínio lógico, resolução de problemas, autonomia, dentre outras?";

- 3) "Você costuma verificar a satisfação dos estudantes em relação às atividades propostas nas aulas remotas?"; e

- 4) "Você recebeu feedback dos pais sobre o desempenho escolar dos filhos nas atividades remotas?".

Para responder as questões a1 à a4 foi utilizada uma descrição livre dos docentes. Para as demais questões foi utilizada uma escala Likert de 10 pontos. Em relação às atividades que o docente faz uso dos recursos tecnológicos (a1), como pode ser observado na Figura 2, 25,2\% $(\mathrm{N}=233)$ responderam fazer uso para estudar novos conteúdos e/ou aprimorar conhecimentos, 25,1\% ( $\mathrm{N}=232)$ realizar pesquisas, $25 \%(\mathrm{~N}=231)$ elaborar material pedagógico, $14,1 \%(\mathrm{~N}=130)$ contactar a administração escolar e $9 \%(\mathrm{~N}=83)$ contactar pais de estudantes. Das atividades com menor uso de recursos tecnológicos, se destacaram: $0,4 \%(\mathrm{~N}=4)$ apresentar conteúdo aos estudantes, $0,4 \%(\mathrm{~N}=4)$ atendimento acadêmico, $0,4 \%(\mathrm{~N}=4)$ avaliar atividades e assistir vídeo-aulas. Esse resultado demonstra que os recursos tecnológicos são mais utilizados para preparação de aula e aquisição de novos conhecimentos, porém pouco utilizados para apoiar os docentes nos processos de ensino e aprendizagem, e realização de atividades práticas com os estudantes.

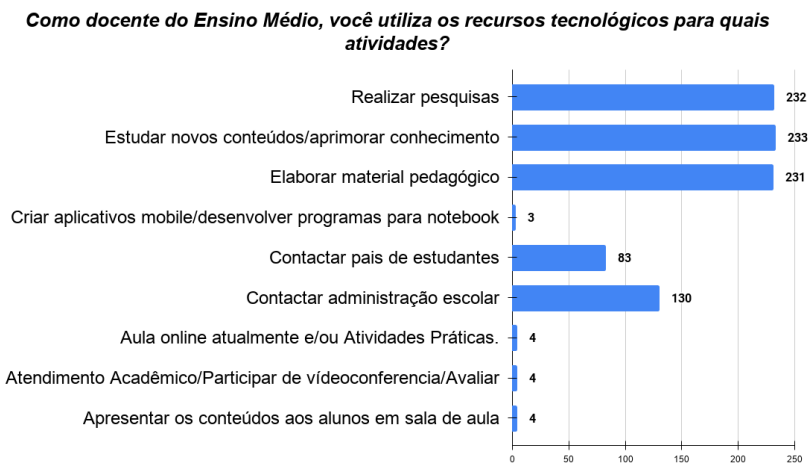

Figura 2: Atividades onde os recursos tecnológicos são utilizados

Referente aos equipamentos tecnológicos utilizados pelos docentes para realizar as atividades remotas de ensino durante o distanciamento social (a2), 51,5\% ( $\mathrm{N}=218)$ são dispositivos móveis, $43,5 \%(\mathrm{~N}=184)$ disseram utilizar computador desktop e/ou notebook, $5 \%(\mathrm{~N}=21)$ disseram fazer uso da televisão.

A Figura 3 apresenta os resultados referentes aos recursos utilizados pelos docentes para ministrar as aulas para os estudantes durante as atividades remotas (a3). Os resultados mostram que 40,5\% $(\mathrm{N}=192)$ utilizam aplicativos de troca de mensagem como Whatsapp e Telegram, 22,7\% ( $\mathrm{N}=108)$ utilizam Ambiente Virtual de Aprendizagem, $20 \%(\mathrm{~N}=95)$ utilizam plataformas de videoconferência e 16,8\% $(\mathrm{N}=80)$ disseram fazer uso das redes sociais.

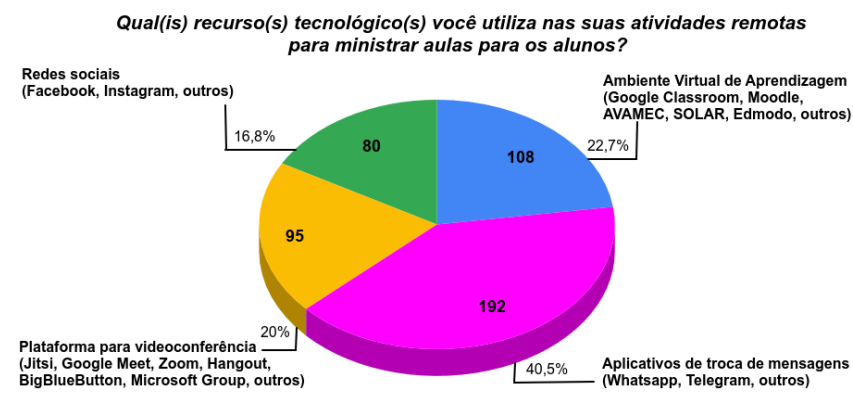

Figura 3: Recursos tecnológicos utilizados para ministrar aula durante as atividades remotas 
Qual(is) recurso(s) tecnológico(s) você utiliza para apoiar suas atividades remotas?

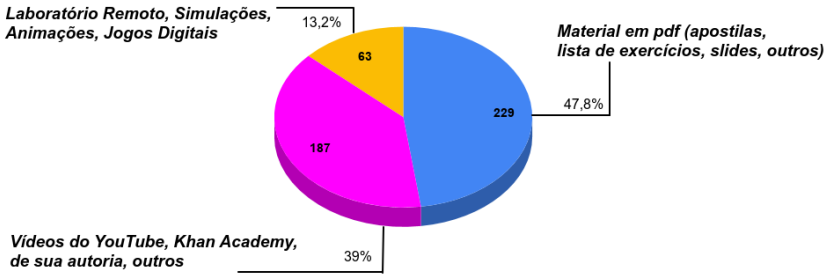

Figura 4: Recursos tecnológicos utilizados como apoio ao ensino remoto.

A Figura 4 apresenta os resultados referentes aos recursos utilizados pelos docentes para apoiar aulas remotas (a4). Os resultados mostram que 47,8\% (N=229) utilizam materiais em pdf, 39\% (N=187) utilizam vídeos do YouTube, Khan Academy, e outros, e 13,2\% (N=63) disseram fazer uso de laboratório remoto, simulações, animações e jogos digitais. Com base nos resultados de a2, a3 e a4, percebeuse que mesmo o docente tendo acesso a equipamentos e recursos tecnológicos, a forma de ensinar ainda está alinhada ao modelo de educação tradicional, mesmo utilizando os recursos tecnológicos. De fato, os docentes utilizam os recursos para realizar pesquisas, aprimorar conhecimento e contactar pais de estudantes e direção escolar. Além disso, faz uso de dispositivos móveis e aplicativos de mensagem como ferramenta para ministrar aula remotamente. E, essas práticas foram acentuadas devido a pandemia, passando-se a utilizar os recursos tecnológicos com mais frequência. No entanto, identificou-se que os materiais utilizados como apoio ao ensino remoto são materiais em pdf (apostilas, listas de exercícios, slides, outros), o que indica que os processos de ensino e aprendizagem ainda são pouco dinâmicos, e consequentemente, podem ser pouco significativo para o contexto de vida do estudante. Dessa maneira, acredita-se que os modos de ensinar e aprender estejam passando por uma transição entre uma Educação 2.0 e Educação 3.0.

Em relação a experiência dos docentes nas atividades remotas (a5), a pergunta "Como você considera a sua experiência nas atividades remotas com os estudantes?" continha 06 indicadores, tais como: (a) Desinteressante/Interessante (percepção sobre o nível de interesse para conduzir atividades remotas); (b) Pouco criativo/Criativo (percepção sobre a demonstração da criatividade para trabalhar usando os recursos tecnológicos); (c) Desconfortável/ Confortável (percepção sobre o grau de conforto para executar atividades remotas); (d) Ineficiente/Eficiente (percepção sobre a eficiência das atividades remotas para apoiar os processos de ensino e aprendizagem); (e) Desmotivante/Motivante (percepção sobre a motivação percebida durante as atividades remotas); e (f) Difícil/Fácil (percepção sobre suas dificuldades na condução das atividades remotas). A Figura 5 apresenta a visão geral sobre as experiências dos docentes nas atividades remotas com os estudantes do Ensino Médio. Em relação a Figura 5a, sobre quanto o docente considera Interessante conduzir às atividades remotas, sendo: 1 "Desinteressante" e 10 "Interessante", 12 participantes consideraram totalmente desinteressante e 15 totalmente interessante. Desse mesmo modo,
53 respondentes consideraram nem interessante e nem desinteressante conduzir as atividades remotas. De modo geral, as respostas mostram que a maioria dos participantes demonstraram que a experiência foi interessante, havendo uma maior concentração de respostas positivas no intervalo de 6 a 10. Portanto, foi percebida que as atividades remotas nas instituições de ensino, mesmo que realizadas de forma improvisada devido o distanciamento social, podem estar criando uma situação favorável para se estabelecer uma cultura digital nas escolas, levando a refletir sobre a necessidade do uso dos recursos tecnológicos a aprendizagem dos estudantes. Esta prática aliada à capacitação docente pode aumentar o interesse para o uso dos recursos tecnológicos, uma vez que estes recursos podem contribuir com os processos de ensino e aprendizagem.

Em relação a Figura 5b, sobre quanto o docente se considera Criativo ao conduzir às atividades remotas, sendo: 1 "Pouco Criativo" e 10 "Criativo", 9 participantes consideraram totalmente Pouco criativo e 12 consideraram totalmente Criativo. Além disso, 51 dos respondentes consideraram a experiência nem Criativa e nem Pouco criativa. As respostas demonstram que a maioria dos participantes se consideraram criativos, havendo uma maior concentração de respostas positivas no intervalo de 6 a 10. Portanto, isso pode significar que o docente está buscando novas estratégias para atingir os objetivos educacionais das aulas realizadas de maneira remota.

Em seguida, no que diz respeito a experiência ser Confortável (Figura 5c), onde 1 significa "Desconfortável" e 10 "Confortável", 19 participantes consideraram totalmente Desconfortável e 10 consideraram totalmente Confortável. Desse mesmo modo, 52 respondentes consideraram nem confortável e nem desconfortável. Nesse sentido, as respostas apresentam que a maioria dos participantes demonstraram a experiência Confortável, havendo uma maior concentração de respostas positivas no intervalo de 7 a 10. Sendo assim, este resultado pode significar que alguns participantes têm certa familiaridade com os recursos tecnológicos, usando-os de forma mais efetiva e mais frequente. Contudo, foram observadas também que as respostas no intervalo de 1 a 4 , representa um número considerável de participantes com experiência negativa. Este resultado pode indicar que parte dos docentes não se sentem confortáveis para utilizar os recursos tecnológicos, mesmo tendo algum tipo de formação.

Sobre a Eficiência das atividades remotas (Figura 5d), onde 1 significa "Ineficiente" e 10 "Eficiente", 26 participantes consideraram totalmente Ineficiente e 12 consideraram totalmente Eficiente. Em contrapartida, 57 consideraram a experiência nem Ineficiente, nem Eficiente. Desse modo, foi percebida no intervalo de 6 a 10 que a maioria dos participantes demonstraram a experiência nem eficiente, nem ineficiente. Este resultado pode ter influenciado na experiência Motivação (Figura 5e), onde 1 significa "Desmotivante" e 10 "Motivante". No que diz respeito à Motivação, 21 participantes consideraram totalmente Desmotivante e 18 consideraram totalmente Motivante. Em contrapartida, 57 consideraram a experiência nem Desmotivante, nem Motivante. Portanto, foi identificado um número expressivo de afirmações negativas no intervalo de 1 a 4 , bem como no ponto 5 que representa neutralidade. A pouca motivação demonstrada pelo docente pode estar relacionado a sua insegurança no uso dos recursos tecnológicos, além de poucas competências e habilidades, como a capacidade para o manusear os recursos tecnológicos. Outros fatores que podem influenciar na 


\section{Como você considera a sua experiência nas atividades remotas com os estudantes?}

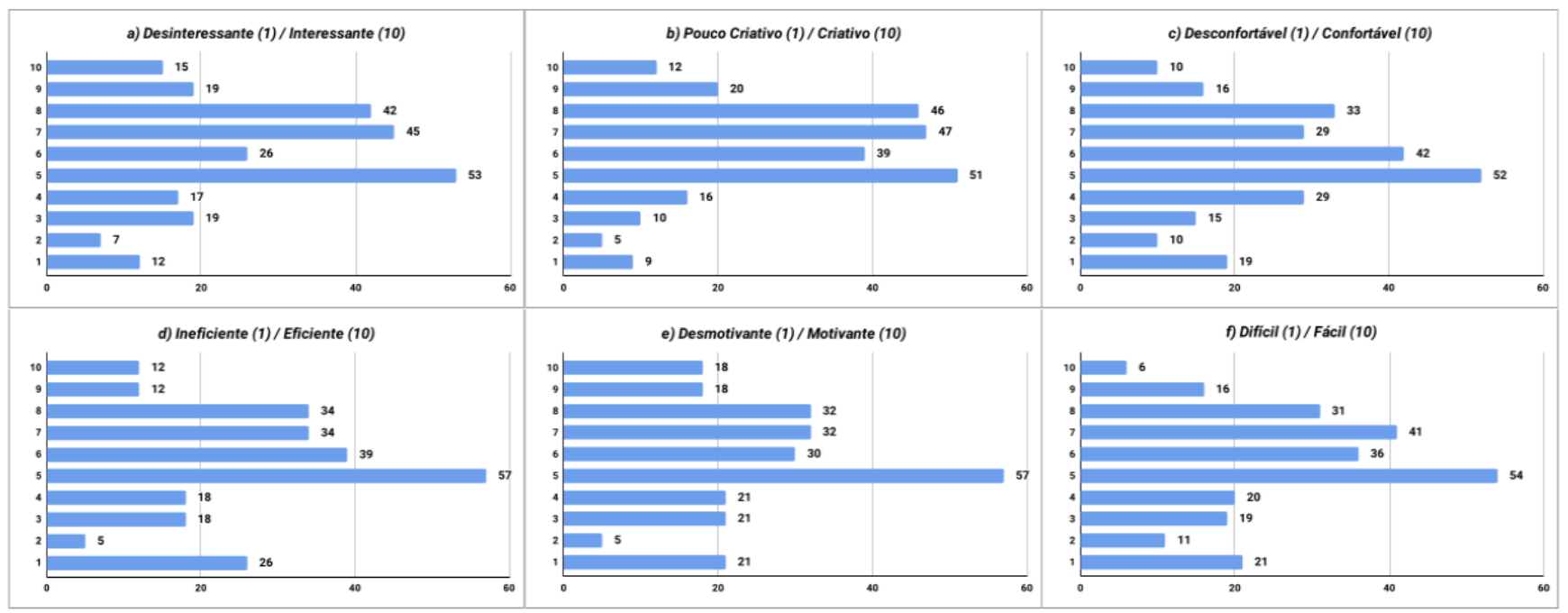

Figura 5: Experiência de docentes nas atividades remotas com estudantes

eficiência e na motivação do docente, são as péssimas estruturas físicas para atividades remotas, precariedade dos equipamentos, má conexão com a Internet, dentre outros.

Em relação às dificuldades dos docentes (Figura 5f), onde 1 significa "Difícil" e 10 "Fácil", 21 destes participantes afirmaram que tiveram muita dificuldade. Nesse sentido, 6 participantes consideraram a experiência totalmente Fácil. Em contrapartida, 54 consideraram nem Fácil, nem Difícil conduzir atividades remotas. Assim como mencionado nas demais experiências, outros motivos podem ter provocado para que os docentes tenham mais dificuldades em conduzir as atividades remotas, tais como: pouca dedicação ou falta de participação dos estudantes, a falta de motivação e engajamento percebidas nas aulas, dentre outras. Desse modo, se faz necessário identificar também quais dificuldades são enfrentadas pelos estudantes no processo de aprendizagem para verificar de que forma esses problemas podem ser minimizados.

A Figura 6a apresenta os resultados referentes à avaliação do docente sobre a sua adaptação do ensino presencial para o ensino remoto (a6), onde 1 significa "Ruim" e 10 significa "Bom". Além disso, a Figura $6 \mathrm{~b}$ apresenta os resultados referente ao grau de dificuldade do docente nas atividades remotas (a7), sendo 1 (não tive dificuldade) e 10 (tive muita dificuldade). Referente a Figura 6a, 13 docentes responderam que sua adaptação foi totalmente Ruim, 20 conside-raram como totalmente Bom, e 44 participantes responderam que não foi nem Ruim e nem Bom. Sobre a Figura 6b, 8 participantes disseram ter muita dificuldade, em contrapartida, 45 participantes responderam que não tiveram dificuldade. Além disso, 53 docentes se demonstraram neutros em relação às dificuldades. Do total de 255 participantes, 29 eram professores da área de Informática e devido à formação demonstraram menos dificuldades em relação aos professores de áreas não específicas. De modo geral, os resultados mostram que alguns participantes tiveram uma boa adaptação, porém uma pequena parte dos respondentes disseram ter muita dificuldade ao utilizar os recursos tecnológicos. Essas dificuldades podem ter influenciado nas respostas dos docentes sobre as suas experiências na condução de atividades remotas, como mostradas anteriormente.

A Figura 7a apresenta a percepção dos docentes em relação a criatividade dos estudantes (b1) percebidas nas atividades propostas, como solucionar desafios-problemas e tomar decisões (sendo 1 "Discordo Totalmente" e 10 "Concordo Totalmente"). Além disso, a Figura $7 \mathrm{~b}$ apresenta a percepção dos docentes em relação ao desenvolvimento das demais competências e habilidades do Século XXI (b2) (sendo 1 "Não percebi" e 10 "Percebi"). Em relação a Figura 7a, 33 participantes discordaram totalmente sobre a demonstração da criatividade dos estudantes nas aulas remotas, 12 concordaram totalmente com a afirmação, em contrapartida, 35 participantes não concordam, nem discordam com a afirmação. Desse modo, os resultados indicam que a maioria dos docentes acredita que os estudantes não foram criativos, havendo uma maior concentração de respostas negativas no intervalo de 1 à 4 do que respostas positivas no intervalo de 7 a 10 . No que diz respeito a Figura 7b, 26 participantes afirmaram que não perceberam o desenvolvimento de competências e habilidades, enquanto 11 responderam ter percebido. De modo geral, as respostas da Figura $7 \mathrm{~b}$ demonstraram que a maioria dos participantes não perceberam o desenvolvimento de competências e habilidades do Século XXI, havendo uma maior concentração de respostas negativas no intervalo de 1 a 4 . Os resultados das Figuras 7a e 7b indicaram que os docentes não perceberam o desenvolvimento tanto da criatividade quanto das demais competências e habilidades do Século XXI, como concentração, autonomia, motivação e aprender a aprender, importantes para esse processo de aprendizagem de maneira remota e preparação dos estudantes para o mundo contemporâneo.

Posteriormente, quando perguntado sobre a satisfação dos estudantes nas atividades remotas (b3), 25,5\% (N=65) docentes disseram não verificar a satisfação dos estudantes, e 74,5\% (N=190) costumam verificar a satisfação. Este resultado demonstra uma preocupação 

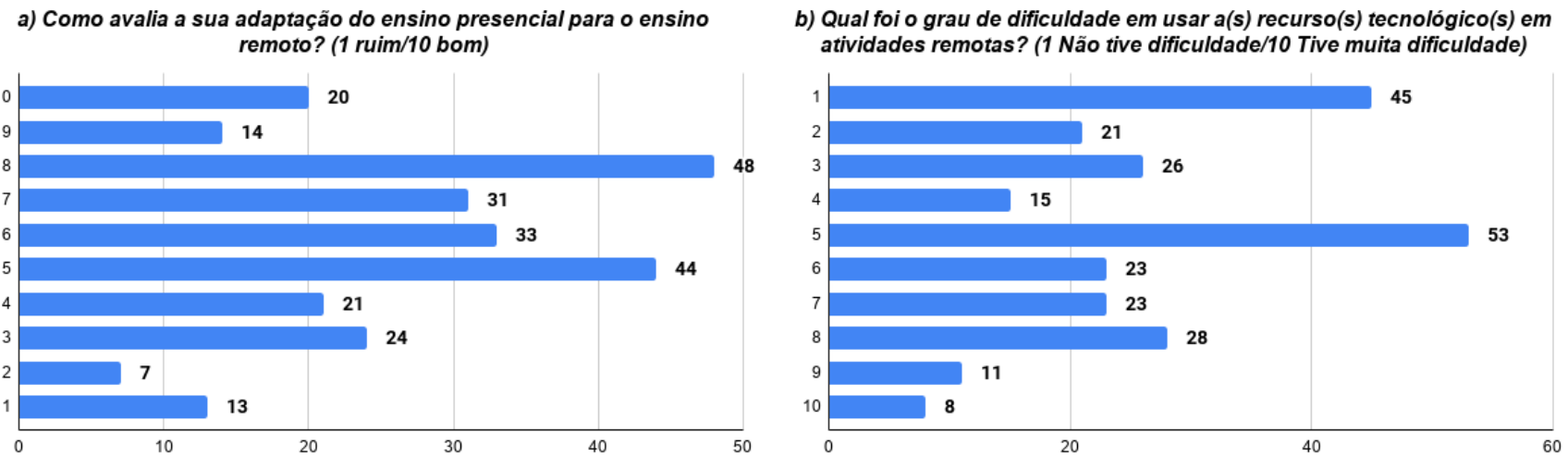

Figura 6: Adaptação no ensino remoto por docentes e grau de dificuldade
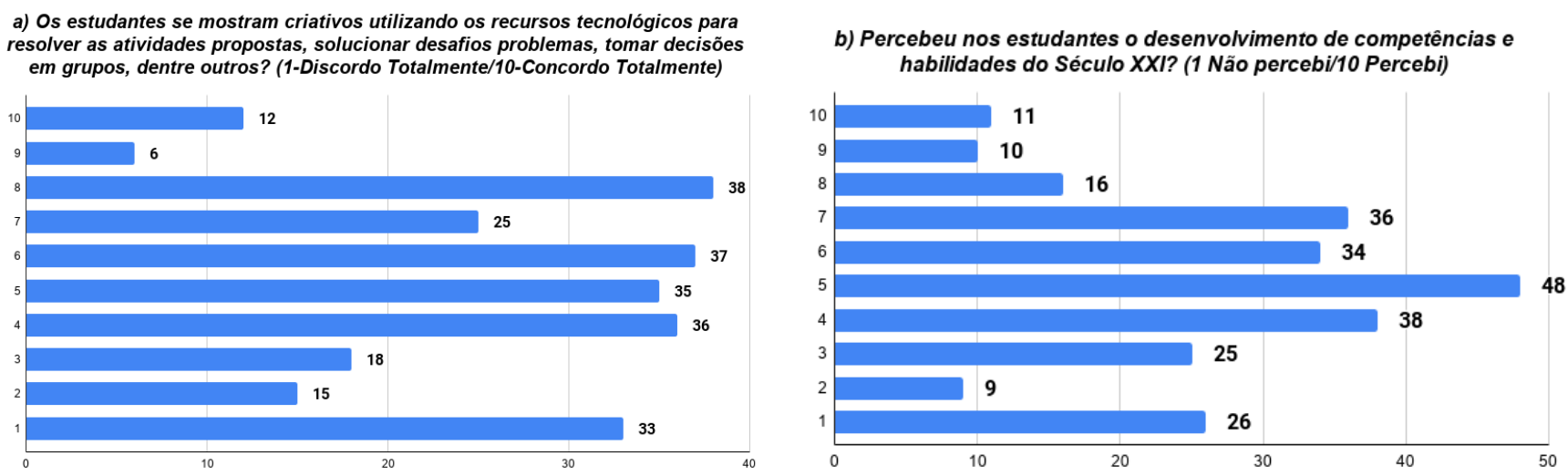

Figura 7: Criatividade e Desenvolvimento de competências e habilidades nos estudantes nas atividades remotas

dos docentes em relação a aprendizagem dos seus estudantes, pois o feedback é a única forma de verificar a eficiência das atividades propostas pelos docentes e se elas estão atingindo os objetivos de aprendizagem. Desse modo, acredita-se que o ensino pode ser planejado para trazer o estudante para o centro do processo de aprendizagem, tornando-o protagonista e responsável pela construção do conhecimento, tendo sua participação ativa.

Além disso, quando perguntado aos docentes sobre o feedback dos responsáveis em relação ao desempenho escolar dos filhos nas atividades remotas (b4), 22,7\% ( $\mathrm{N}=58)$ docentes disseram receber feedback, enquanto 77,3\% (N=197) disseram não receber. Estes resultados demonstram que há pouca participação dos pais no acompanhamento dos seus filhos durante às atividades remotas. Esta situação pode dificultar ainda mais o processo de aprendizagem dos estudantes, pois sem o incentivo dos pais, somado a outras dificuldades enfrentadas pelos estudantes, o ensino remoto pode pouco acrescentar na aprendizagem.

\section{CONSIDERAÇÕES FINAIS}

Este trabalho apresentou os resultados de uma pesquisa de opinião sobre a experiência dos docentes no processo de adaptação e condução de atividades remotas durante o período de distanciamento social. Nesse sentido, foi percebido que o docente foi desafiado a utilizar os recursos tecnológicos de forma mais efetiva e buscar novas estratégias de ensino e aprendizagem, fazendo-o repensar sobre o modelo e os métodos tradicionais de ensino. Assim, acredita-se que as características da Educação 4.0 podem contribuir nesse contexto, permitindo a preparação dos estudantes através da personalização da aprendizagem e flexibilidade do currículo, além do desenvolvimento das competências e habilidades requeridas no Século XXI, e nitidamente importantes para os estudantes nas atividades remotas como: criatividade, boa comunicação, autonomia, concentração, trabalho em equipe, motivação, autorregulação, dentre outras.

Com base na análise desta pesquisa de opinião foi possível perceber que os docentes do Ensino Médio têm algum conhecimento sobre o uso dos recursos tecnológicos, mas que ainda sentem algum grau de dificuldade ou insegurança no uso destes recursos. Falta de equipamentos, má qualidade da internet e a falta de apoio de um 
profissional de tecnologia educacional podem ser fatores que influenciam a pouca utilização dos recursos tecnológicos nos processos de ensino e aprendizagem. Além disso, foi identificado que alguns docentes se sentem desmotivados nas aulas remotas, o que pode estar relacionado ao pouco conhecimento sobre as diferentes abordagens e tecnologias educacionais, além de poucas competências e habilidades do Século XXI. Adicionalmente, foram verificados que alguns respondentes consideraram a experiência remota criativa e interessante, indicando que alguns docentes podem estar buscando novas estratégias para conduzir aulas remotas, seja por meio do uso de aplicativos de troca de mensagem e/ou redes sociais ou via ambiente virtual de aprendizagem.

Este artigo pode contribuir para compreensão do cenário atual do ensino remoto no Ensino Médio com base na experiência do docente em ministrar aulas por meio de recursos tecnológicos. De modo geral, foram percebidos que alguns docentes tiveram uma experiência positiva no processo de adaptação do ensino presencial para o ensino remoto. No entanto, outros apresentaram dificuldades, que podem estar relacionadas ao pouco engajamento dos estudantes, além da falta de competências e habilidades para utilizar recursos tecnológicos. Novas pesquisas precisam ser feitas a fim de investigar como docentes podem ensinar remotamente de forma mais criativa e motivadora, contribuindo assim, para o desenvolvimento dessas competências e habilidades esperadas para o Século XXI.

\section{AGRADECIMENTOS}

Agradecemos aos docentes do Ensino Médio pela participação nessa pesquisa de opinião. À professora Dra. Marialina Corrêa Sobrinho pelo apoio e dedicação na divulgação desta pesquisa de opinião. Esta publicação foi escrita com apoio financeiro da Coordenação de Aperfeiçoamento de Pessoal de Nível Superior (CAPES).

\section{REFERENCIAS}

[1] Cláudio de Oliveira. Tic's na educação: a utilização das tecnologias da informação e comunicação na aprendizagem do aluno. Pedagogia em Ação, 7(1), 2015.

[2] Deivid Eive dos Santos Silva, Marialina Corrêa Sobrinho, and Natasha Valentim. Criação de jogos educacionais para apoiar o ensino da matemática: um estudo de caso no contexto da educação 4.0. In Anais do Workshop de Informática na Escola, volume 25, page 1179, 2019.

[3] Regina Candida Führ and Wagner Roberto Haubenthal. Educação 4.0 e seus impactos no século xxi. Educação no Século XXI-Volume 36 Tecnologia, page 61, 2019.

[4] Gabriel Loureiro de Lima, Niltom Vieira Junior, José Geraldo Ribeiro Júnior, Elzo Alves Aranha, Jorge Candido, Américo Tristão Bernardes, José Silvério Edmundo Germano, and Adriana Maria Tonini. Desafios da educação em engenharia: formação acadêmica e atuação profissional, práticas pedagógicas e laboratórios remotos. 2017.

[5] Regina Candida Führ. O dilúvio digital e seus impactos na educação 4.0 e na indústria 4.0. Investigação em Governança Universitária: Memórias, 188:37-54, 2018.

[6] CGI. Tic educação 2018: cresce interesse dos professores sobre o uso das tecnologias em atividades educacionais. Disponível em: < bit.ly/3gBlsau>. Acessado em 03 jun. 2020, 2019.

[7] CIEB. Aprendizagem remota impõe uma reinvenção das práticas pedagógicas. Disponível em: < http://cieb.net.br/praticas-pedagogicas $>$. Acessado em 20 jun. $2020,2020$.

[8] Hudson do Vale de Oliveira and Francimeire Sales de Souza. Do conteúdo programático ao sistema de avaliação: reflexões educacionais em tempos de pandemia (covid-19). Boletim de Conjuntura (BOCA), 2(5):15-24, 2020.

[9] PISA. Brasil no pisa 2015: Análises e reflexões sobre o desempenho dos estudantes brasileiros. Disponível em: <https://bit.ly/2DotVQ0>. Acessado em 30 jul. 2020, 2015.

[10] SAEB. Relatório saeb 2017. Disponível em: < https://bit.ly/30cgafW>. Acessado em 30 jul. 2020, 2017.
[11] PISA. Relatório brasil no pisa 2018, versão preliminar. Disponível em: < https: //bit.ly/2ExT3Eh>. Acessado em 30 jul. 2020, 2018.

[12] Vichian Puncreobutr. Education 4.0: New challenge of learning. St. Theresa Journal of Humanities and Social Sciences, 2(2), 2016.

[13] Deivid Eive Silva, Marialina Correa Sobrinho, and Natasha Malveira Valentim. Educação 4.0: um estudo de caso com atividades de computação desplugada na amazônia brasileira. Anais do Computer on the Beach, 11(1):141-147, 2020.

[14] Enoque Fôro de Oliveira. Ensino de geografia e educação 4.0: Caminhos e desafios na era da inovação. Revista Amazônica sobre Ensino de Geografia, 1(01), 2019.

[15] Juliana E Murofushi and Maria AM Barreto. Educação 4.0 na engenharia: percepção dos docentes de 3 universidades brasileiras/education 4.0 in engineering: perception of professors from 3 brazilian universities. Brazilian fournal of Development, 5(9):15255-15266, 2019.

[16] Amarildo Enes dos Santos, Carlos Antonio de Oliveira, and Elma Nunes de Carvalho. Educação 5.0: uma nova abordagem de ensino-aprendizagem no contexto educacional. 2019.

[17] José Cláudio Securato. Onlearning: como a educação disruptiva reinventa a aprendizagem. Saint Paul, 2019.

[18] Nur Fazirah Jumari, Khairiyah Mohd-Yusof, and Fatin Aliah Phang. Metacognitive development in engineering students through cooperative problem based learning (cpbl). In Engineering Education for a Smart Society, pages 107-120. Springer, 2016

[19] Ernandes Rodrigues do Nascimento, Maria Auxiliadora Padilha, Cristiane Lucia da Silva, and Fábio Leandro Melo Ramo dos Anjos. Metodologias ativas e engajamento docente: uma reflexão sobre as dificuldades enfrentadas pelos professores da educação superior. Educação Por Escrito, 10(1):e31560-e31560, 2019.

[20] Verissimo Barros dos Santos Junior and Jean Carlos da Silva Monteiro. Educação e covid-19: As tecnologias digitais mediando a aprendizagem em tempos de pandemia. Revista Encantar-Educação, Cultura e Sociedade, 2:01-15, 2020.

[21] Alessandra Conceição Leite Funchal Camacho, Fabiana Lopes Joaquim, Harlon França de Menezes, and Rosana Moreira Sant'Anna. Tutoring in distance education in times of covid-19: relevant guidelines. Research, Society and Development, 9(5):30953151, 2020.

[22] Nova Escola. "a situação dos professores no brasil durante a pandemia". Disponível em: < https://bit.ly/3ghd53W>. Acessado em 03 de junho de 2020, 2020.

[23] Jonathan Lazar, Jinjuan Heidi Feng, and Harry Hochheiser. Research methods in human-computer interaction. Morgan Kaufmann, 2017. 